\title{
The influence of using interval core stability circuit exercise towards strength and recovery
}

\author{
Ariani L.P.T. ${ }^{1 \mathrm{ABD}}$, Setijono H. ${ }^{2 \mathrm{AC}}$ \\ ${ }^{1}$ Department of Sports Training Education, Ganesha University of Education, Bali, Indonesia \\ ${ }^{2}$ Department of Sports Training Education, State University of Surabaya, Indonesia
}

\begin{abstract}
Authors' Contribution: A-Study Design, B-Data Collection, C-Statistical Analysis, D-Manuscript Preparation, E-Funds Collection
\end{abstract}

\begin{abstract}
Purpose: $\quad$ The study aimed to know the influence of using interval in core stability circuit towards the enhancement of strength and recovery.

Material: $\quad$ The participants in this study were students of Coaching Education, Faculty of Sport Science.. The participants were consisting of 20 male students with range of age in 18-21 years old. These students were divided into two groups, each group consisted of 10 students. This study used experimental research with the randomized pre and posttest design, in which the treatment group 1 was given the core stability circuit exercise with 1:1 interval. Then, the core stability circuit exercise with 1:2 interval was given to the treatment group 2 . The variable in this study focused on the strength and the recovery. The data were analyzed using descriptive analysis, requirement test analysis and inferential analysis.

Results: $\quad$ The result showed that there was an enhancement in leg, stomach, and arm muscle strength and recovery of Sports Coaching Education's students 2015, Faculty of Sport Science UNESA (State University of Surabaya). Based on the normality and homogeneity test, the data was claimed as normal and homogeny. Whereas the counting result of differences test in all variables showed that there were differences between the mean result of 1:1 interval exercise and 1:2 interval exercises toward the strength of leg, stomach, arm muscle, and recovery.

Conclusions: Core stability exercise was able to increase the physical performance of arm, leg, and stomach muscle strength. It could be applied with circuit and high intensity of interval training to enhance the recovery ability.

Keywords: circuit exercise, core stability, interval, muscle strength, recovery.
\end{abstract}

\section{Introduction}

The sport teaching through long, sustainable, and systematic exercise process can lead somebody to reach for champion and success. A target in sport teaching is the goal to be reached. Meanwhile, the inability to accomplish the goal is something that must be reviewed and evaluated. In sport teaching, physical aspect is the main thing in reaching for achievement, "The stronger the physical foundation the greater the potential for developing technical, tactical, and psychological attributes" [1]. The application of exact and effective methodology is the main key to produce professional athletes.

Physical ability is the basis sport ability while shaping a perfect technic and tactic is the most important part in sport. The physical components including strength, elasticity, and balance have function to increase the whole physical capacity. All muscles can work well and harmonic if it was trained in the beginning [2].

In the world of sport, there are kinds of exercise methodology to train the physical components in an exercise program. The quality of an exercise is influenced by the ability in designing the exact and advantageous exercise program. The components should be concerned on the exercise time, the inter-set break, the interval, the amount of set, and the circuit [3]. Interval is the significant way to be included in the whole exercise program while the training circuit is the best way to increase the

\footnotetext{
(C) Ariani L.P.T., Setijono H., 2018
}

doi:10.15561/20755279.2018.0603 mobility, power, and stamina. The benefits of training circuit enhance the physical components synchronously in a brief time, controllable, time saving and can be done by many people [4]. The bio motoric component needs the power of muscle to balance the body position and movement in sport. According to Kibler, core stability is an exercise model to increase the ability of controlling the body position through hip and feet to produce the optimal movement possibility [5]. Granacher, et al stated that the core muscle strength is the important requirement in some branches of sports in track, field, hiking, or football. It is because, anatomically, the muscle has contact with stomach in the front side, Para spinal, and gluts behind [6]. Having the ability of fast recovery will help the regenerating process, lowering fatigue, increasing super compensation and decreasing the risk of injury and over training. Starting from the explanation previously, there must be an observation regarding to the influence of using interval in core stability circuit towards the enhancement of strength and recovery.

\section{Hypothesis}

1. There was significant influence of the interval use $1: 1$ Core Stability Circuit exercise towards strength.

2. There was significant influence of the interval use $1: 2$ Core Stability Circuit exercise towards recovery.

3. There was significant interaction of the weight training circuit exercise and core stability circuit exercise with $1: 1$ and 1:2 interval toward strength and recovery. 


\section{Purpose}

1. Knowing the significant influence of the interval use 1:1 Core Stability Circuit exercise towards the strength.

2. Knowing the significant influence of the interval use 1:2 Core Stability Circuit exercise towards recovery.

3. Knowing the significant interaction of the weight training circuit exercise and core stability circuit exercise with 1:1 and 1:2 interval toward strength and recovery.

\section{Material and methods}

\section{Participants}

The participants in this study were students of Coaching Education, Faculty of Sport Science, State University of Surabaya year 2015. The participants were consisting of 20 male students with range of age in 18-21 years old. These students were divided into two groups, each group consisted of 10 students.

\section{Research Design}

This study used experimental research applying The Randomized Pre and Post Test Design by Pocock [7]. The treatment was given to two groups. Group 1, consisted of 10 male students, was given the core stability circuit exercise with 1:1 interval. Then, the core stability circuit exercise with 1:2 interval was given to the treatment group 2 composed of 10 male students. The variable in this study focused on the strength and the recovery. The data were analyzed using descriptive analysis, requirement test analysis and inferential analysis. The research design would be as the following figure below.

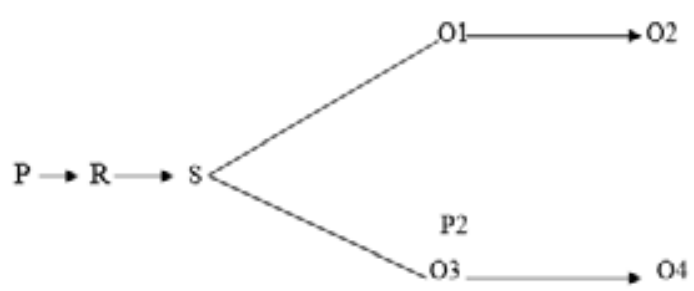

Figure 1. The research design

P: PopulationR: Random;

S: SamplingO: Observation of strength and recovery;

P1: The Treatment Group 1, core stability circuit exercise with 1:1 interval;

P2: The Treatment Group 2, core stability circuit exercise with 1:2 interval;

01: Observation of strength and recovery group -1 before the core stability circuit exercise with 1:1 interval; O2: Observation of strength and recovery group -1 after the core stability circuit exercise with 1:1 interval; O3: Observation of strength and recovery group -2 before the core stability circuit exercise with 1:2 interval; 04: Observation of strength and recovery group -2 after the core stability circuit exercise with 1:2 interval;

\section{Statistical analyses} elow;
1. The Normality Test of strength and recovery using Shapiro-Wilk Test had purpose to know the data distribution in each treatment groups.

2. The Homogeneity Test of strength and recovery before and after the treatment using Lavene Test had purpose to know the data variation.

3. The Different Test

a. T-Paired Test was used to analyze the mean of strength and recovery enhancement before and after the treatment in each group

b. Wilcoxon Test was used to analyze the non-normal distributed data.

The normal distributed data used parametric statistic test or T-Independent Test in significance standard $p=$ 0.05 to compare the exercise impact in group 1 .

\section{Results}

The Requirement of Hypothesis Test

Before doing the hypothesis test, there are two requirements need to be done. First, the data must be in normal distribution. Second, the data must be homogeny. Therefore, the normality and homogeneity test should be done at first.

Normality Test

Normality Test was using Shapiro-Wilk Test.

The table above showed that the value of sig. was bigger than 0.05 in general. Thus, it can be concluded that all the data above were normal distributed data.

Homogenity Test

The Homogenity Test was used to know the similarity of the variant from some population.

The table 2 above showed the variety of homogeny data. Since the test criteria was the value of sig. is bigger than 0.05 , it can be concluded that all variables from the groups had same variation or homogeny.

\section{Hypothesis Test}

The hypothesis test was done to answer the problem offered in this study. The data were obtained from the test given to the respondents. Thus, the result will be proceed and analyzed statistically to test the hypothesis done before.

\section{The Paired Sample T-Test}

The Paired Sample T-Test was used to test the differentiation on paired up sample.

Table 3 above displayed the counting result of Paired Sample T-Test. The variable of leg muscle (leg), stomach muscle (sit), arm muscle (push), and recovery (rec) in Core Stability group with 1:1 interval had the mean sig. value bigger than 0.05 , which accepted the Ho. Also, there was no significant discrepancy among the power of leg muscle, stomach muscle, arm muscle, and recovery before and after the exercise.

In the Core Stability group with 1:2 interval, the variable of leg muscle (leg) and recovery (rec) had the mean sig. value more than 0.05 or sig. $>0.05$ by accepting the Ho. Thus, there were no significant differences between the leg muscle and recovery before and after the exercise. On the other sides, the variable of stomach muscle (sit) and arm muscle (push) had the mean sig. less 


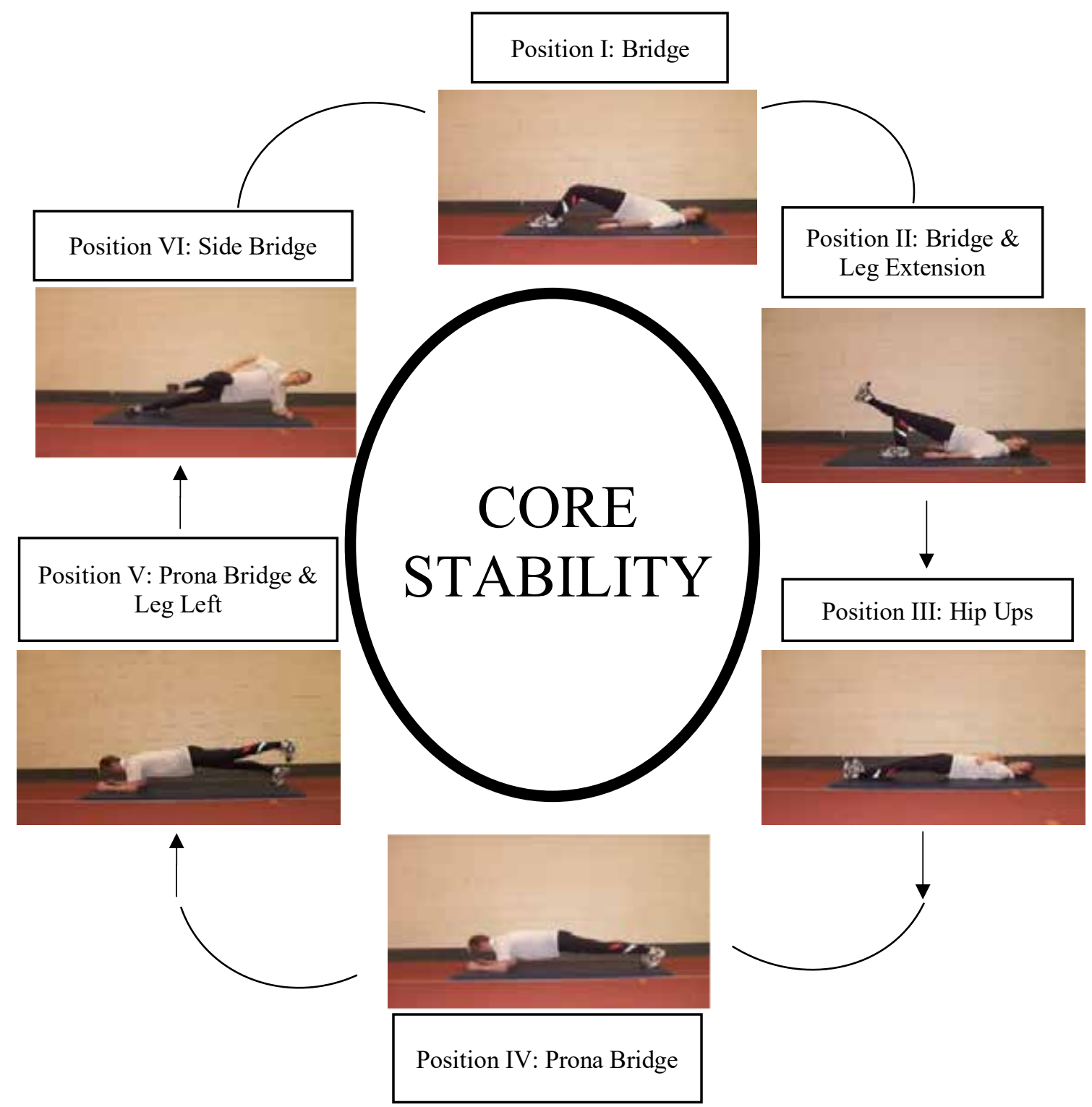

Figure 2. Core Stability Circuit

Table 1. The Result of Normality Test

\section{Test of Normality}

Core Stability 1:1

Core Stability 1:2

\begin{tabular}{lcllllll}
\hline Leg Muscle Strength & Pre-Test & $\begin{array}{l}\text { Post- } \\
\text { Test }\end{array}$ & $\begin{array}{l}\text { Delta- } \\
\text { Test }\end{array}$ & Leg Muscle Strength & $\begin{array}{l}\text { Pre- } \\
\text { Test }\end{array}$ & $\begin{array}{l}\text { Post- } \\
\text { Test }\end{array}$ & $\begin{array}{l}\text { Delta- } \\
\text { Test }\end{array}$ \\
$\begin{array}{l}\text { Sig. } \\
\begin{array}{l}\text { Stomach Muscle } \\
\text { Strength }\end{array}\end{array}$ & 0.273 & 0.305 & 0.305 & Sig. & 0.230 & 0.480 & 0.918 \\
Arm Muscle Strength & 0.571 & 0.692 & 0.061 & $\begin{array}{l}\text { Stomach Muscle } \\
\text { Strength }\end{array}$ & 0.875 & 0.225 & 0.232 \\
& 0.563 & 0.232 & Arm Muscle Strength & 0.646 & 0.905 & 0.691 \\
Recovery & 0.480 & 0.119 & 0.392 & Recovery & 0.480 & 0.545 & 0.527 \\
\hline
\end{tabular}


Table 2. The Result of Homogenity Test

Test of Homogeneity of Variances

\begin{tabular}{llll} 
Leg Muscle Strength & Pre-Test & Post-Test & Delta \\
\hline Sig. & 0.552 & 0.602 & 0.122 \\
Stomach Muscle Strength & 0.188 & 0.144 & 1.000 \\
Arm Muscle Strength & 0.967 & 0.910 & 0.213 \\
Recovery & 1.000 & 0.526 & 0.286
\end{tabular}

Table 3. The Counting Result of Paired Sample T-Test

\begin{tabular}{|c|c|c|c|}
\hline \multicolumn{4}{|c|}{ Paired Samples Test } \\
\hline \multicolumn{4}{|c|}{ Core Stability 1:1 } \\
\hline Pair 1 & Pre_Leg - Post_Leg & 0.237 & Similar \\
\hline Pair 2 & Pre_Sit - Post_Sit & 0.052 & Similar \\
\hline Pair 3 & Pre_Push - Post_Push & 0.195 & Similar \\
\hline Pair 4 & Pre_Rec-Post_Rec & 0.241 & Similar \\
\hline \multicolumn{4}{|c|}{ Core Stability 1:2 } \\
\hline Pair 1 & Pre_Leg - Post_Leg & 0.336 & Similar \\
\hline Pair 2 & Pre_Sit - Post_Sit & 0.010 & Different \\
\hline Pair 3 & Pre_Push - Post_Push & 0.029 & Different \\
\hline Pair 4 & Pre_Rec-Post_Rec & 0.066 & Similar \\
\hline
\end{tabular}

Table 4. The Result of Independent Sample T-Test of 1:1 and 1:2 interval exercise

\section{Independent Samples Test}

\begin{tabular}{|c|c|c|c|}
\hline & & Sig. (2-tailed) & Information \\
\hline Leg Muscle Strength & Equal Variances Assumed & 0.013 & $\begin{array}{l}\text { Ho rejected } \\
\text { (different) }\end{array}$ \\
\hline Stomach Muscle Strength & Equal Variances Assumed & 0.032 & $\begin{array}{l}\text { Ho rejected } \\
\text { (different) }\end{array}$ \\
\hline Arm Muscle Strength & Equal Variances Assumed & 0.017 & $\begin{array}{l}\text { Ho rejected } \\
\text { (different) }\end{array}$ \\
\hline Recovery & Equal Variances Assumed & 0.033 & $\begin{array}{l}\text { Ho rejected } \\
\text { (different) (similar) }\end{array}$ \\
\hline
\end{tabular}

than 0.05 , which rejected the Ho. Therefore, there was a significant difference between stomach and arm muscle before and after the exercise.

The Independent Sample T-Test

The Independent Sample T-Test was used to observe the dissimilarity between two free samples or unpaired sample. It compared the 1:1 interval Core Stability exercise with $1: 2$ interval exercise against the strength of leg muscle, stomach muscle, arm muscle, and recovery.

All variable, including leg muscle strength, stomach muscle strength, arm muscle strength, and recovery had the sig. value less than 0.05 which rejected the Ho. Hence, it was concluded that there was dissimilarity between the mean result of 1:1 interval exercise and 1:2 interval exercise toward leg, stomach, and arm muscle strength.

\section{Discussion}

The Use of 1:1 Interval on Core Stability Circuit Exercise towards Strength and Recovery.

Strength.

Stabilization is one of the exercise forms for core training or muscle core training. Core stability is the ability to control the body position and movement through hip and feet to optimize the possibility production, transfer, strength and movement to the terminal segment in integrated kinetic activity [5]. The data from cross sectional study showed the significant relationship among the variable of core muscle power, run, throw, and jump of young and healthy individual $[8,9]$. On the other words, the strength ability will be increased along with the right and sequence core muscle training. 
Recovery.

In its practice, the core stability circuit exercise with 1:1 intensity made the break time to move from one post to another post equal with the practice time. In circuit training practice, six posts with Bridge, Bridge \& Leg, Extension, Hip Ups, Prona Bridge, Prona Bridge \& Leg Lift, Side Bridge were used to higher the exercise intensity. With higher intensity and minimum break time, the recovery ability will be increased.

The Use of 1:2 Interval on Core Stability Circuit Exercise towards Strength and Recovery.

According to Akuthota, core muscle exercise is the main requirement for some sports, such as athletic sport or track and field, climbing, and football. It is also found in daily activity such as sit, stand, and walk in straight position $[10,11]$. Core stability is commonly used to strengthen the muscle around the stomach, waist, and hip. The muscle around these areas have important role in stabilizing and controlling the waist posture by using tonic muscle or postural during the body exercise [12]. The muscle that in charge to the core stability exercise were; multifidus muscle, transversus abdominis, abdominis oblik external/ internal, paraspinalis, gluteus, behind part of diafragma, and hip muscle. The ventral, multifidus, transversus abdominis, and oblique abdominis muscle gave core stability through the cooperative contraction before moving. The multifidus muscle had function as intersegmental muscle which placed on spiral part followed by interspinales and intertransverse muscles. These muscles controlled the movement spine unit by lifting the things and while spinning the core. Therefore, the core stability exercise will increase the strength of stomach and leg muscle.

Significant Differences on 1:1 and 1:2 Interval in Giving Strength and Recovery Effect.

Strength.

The interval method had purpose to make or to modify the time break in exercise. The interval commonly used in an exercise was $1: 1$ and 1:2. It had its own goal to increase the physical performance. The long time break for each set was recommended for helping the recovery on nerve system which had impact on the consistency of the movement [13-16]. It was also helping the recovery of the energy system in glycolysis and the removal of biochemical substation from muscle exhaustion. Therefore, in this study, the interval 1:2 was more proper to enhance the strength ability. In core stability exercise, it was suggested not to use short interval time break because it potentially obstructs the recovery energy in muscle.

Recovery.

In core stability circuit exercise with 1:1 intensity made the break period to move from one post to another post equal with the time practice. Through enhancing the intensity and minimizing the time break, the recovery ability on core stability 1:1 is more effective.

Significant Interaction of Core Stability Circuit with 1:1 and 1:2 Interval toward Strength and Recovery.

Based on the analysis, it can be seen that there was interaction or relation between the core stability circuit and interval using. The exercise with circuit method made the exercise more varies and had many posts in one set which then higher the exercise's intensity. Meanwhile, the exercise with high intensity interval might have indirect connection with lung system. But, this exercise probably enhances the strength of the respiration muscle and the expiratory flow rates because it allowed the higher adaption process on the lung ventilation when performing the physical activity.

\section{Conclusion}

Indeed, the result of this study can be concluded that core stability exercise was able to increase the physical performance of arm, leg, and stomach muscle strength. In addition, core stability exercise could be applied with circuit and high intensity of interval training to enhance the recovery. Moreover, the effective exercise method with different ratio can be seen from the goal achieved from the training plan. However, further study should consider the effect of $1: 1 / 2,1: 1$, and $1: 2$ ratio exercise physiologically. Further, keeping the exercise's intensity high by maintaining the heart rate using heart rate monitor.

\section{Conflict of interest}

The authors declare no conflict of interest.

\section{References}

1. Bompa TO, Haff, GG. Periodization Theory and Methodology of Training. United States: Human Kinetics; 2009.

2. Ngurah N. Principles of Sports Physical Training. Bali: Udayana University Press; 2011.

3. Sukadiyanto, Muluk D. Introduction to Theory and Physical Training Methodology. Bandung: Lubuk Agung; 2011.

4. Juliantine. Physical Exercise in Sports and Health Education. Indonesia: Universitas Pendidikan Indonesia; 2007.

5. Kibler WB, Press J, Sciascia A. The Role of Core Stability in Athletic Function. Journal Sport Medicine. 2006; 36(3):189- 198. https://doi.org/10.2165/00007256-200636030-00001

6. Granacher U, Schellbach J, Klein K, Prieske O, Baeyens J-P, Muehlbauer T. Effects of core strength training using stable versus unstable surfaces on physical fitness in adolescents: a

randomized controlled trial. BMC Sports Science, Medicine and Rehabilitation [Internet]. 2014 Dec [cited 2018 Dec 5];6(1). Available from: http://bmcsportsscimedrehabil. biomedcentral.com/articles/10.1186/2052-1847-6-40 https://doi.org/10.1186/2052-1847-6-40

7. Pocock SJ. Clinical Trial a Practical Approach. ChichesterNew York. Singapore: Jon Wiley \& Son Ltd; 2008.

8. Nesser TW, Huxel KC, Tincher JL, Okada T. The Relationship Between Core Stability and Performance in Division I Football Players: Journal of Strength and Conditioning Research. 2008;22(6):1750-4. https://doi.org/10.1519/JSC.0b013e3181874564

9. Tomoko O, Kellie CH, Thomas WN. Relatioship between Core Stability Functional Movement And Performance. Journal Strenght anc Conditioniong Research, 2011; 25(1):252- 261. https://doi.org/10.1519/JSC.0b013e3181b22b3e 
10.Akuthota V, Ferreiro A, Moore T, Fredericson M. Core Stability Exercise Principles. Current Sports Medicine Reports. 2008;7(1):39-44. https://doi.org/10.1097/01.CSMR.0000308663.13278.69

11.Wang X-Q, Zheng J-J, Yu Z-W, Bi X, Lou S-J, Liu $\mathrm{J}$, et al. A Meta-Analysis of Core Stability Exercise versus General Exercise for Chronic Low Back Pain. Eldabe S, editor. PLoS ONE. 2012;7(12):e52082. https://doi.org/10.1371/journal.pone.0052082

12.Marshall PW, Murphy BA. Core stability exercises on and off a Swiss ball. Archives of Physical Medicine and Rehabilitation. 2005;86(2):242-9. https://doi.org/10.1016/j.apmr.2004.05.004

13.Cress Maria, Porcari John, Foster Carl. Interval Training. ACSM's Health \& Fitness Journal. 2015;19(6):3-6.

14.Foster C, Stanley D, de Koning JJ, Porcari JP. Get moving! the first thing you have to do is run more.
ACSM's Health \& Fitness Journal. 2014;18(2):12-8. https://doi.org/10.1249/FIT.0000000000000023

15.Gibala MJ, Heisz JJ, Nelson AJ. Interval training for cardiometabolic and brain health. ACSM's Health \& Fitness Journal. 2018;22(6):30-4. https://doi.org/10.1249/FIT.0000000000000428

16. Roxburgh BH, Nolan PB, Weatherwax RM, Dalleck LC. Is moderate intensity exercise training combined with high intensity interval training more effective at improving cardiorespiratory fitness than moderate intensity exercise training alone? J Sports Sci Med. 2014;13(3):702-7.

17.Lunt H, Draper N, Marshall HC, Logan FJ, Hamlin MJ, Shearman JP, et al. High Intensity Interval Training in a Real World Setting: A Randomized Controlled Feasibility Study in Overweight Inactive Adults, Measuring Change in Maximal Oxygen Uptake. Schooling CM, editor. PLoS ONE. 2014;9(1):e83256. https://doi.org/10.1371/journal.pone.0083256

\section{Information about the authors:}

Ariani L.P.T.; (Corresponding author); http://orcid.org/0000-0002-6258-6524; Ipartini_undiksha@yahoo.com; Department of Sports Training Education, Ganesha University of Education; Pegok, Jalan Raya Sesetan No.196, Sesetan, Denpasar Selatan, Pedungan, Denpasar Sel., Kota Denpasar, Bali 80223, Indonesia.

Setijono H.; Prof. Dr.; http://orcid.org/0000-0002-3297-7938; Harisetijon123@gmail.com; Department of Sports Training Education, State University of Surabaya; Jl. Rektorat Unesa, Lidah Wetan, Lakarsantri, Kota SBY, Jawa Timur 60213, Indonesia.

Cite this article as: Ariani LPT, Setijono H. The influence of using interval core stability circuit exercise towards strength and recovery. Physical education of students, 2018;22(6):298-303. doi:10.15561/20755279.2018.0603

The electronic version of this article is the complete one and can be found online at: http://www.sportedu.org.ua/index.php/ PES/issue/archive

This is an Open Access article distributed under the terms of the Creative Commons Attribution License, which permits unrestricted use, distribution, and reproduction in any medium, provided the original work is properly cited (http:// creativecommons.org/licenses/by/4.0/deed.en).

Received: 12.09.2018

Accepted: 09.10.2018; Published: 26.12.2018 